\title{
Synchronicity in Signage Promotes a Sense of Belonging
}

\author{
Aparna Sundar, Ph.D. Flavia Gonsales, Ph.D. \\ Assistant Professor \\ Department of Marketing, \\ Lundquist College of Business, \\ University of Oregon \\ asundar@uoregon.edu \\ Researcher at Group of Image Studies \\ in Communication (GEIC), \\ Escola de Comunicações e Artes, \\ Universidade de São Paulo \\ flavia_gonsales@usp.br
}

\section{Gracie Schafer}

Undergraduate Student Department of Marketing, Lundquist College of Business, University of Oregon

gschafer@uoregon.edu

\section{INTRODUCTION}

Although images on signage are often two dimensional, the graphics on a sign can communicate complex information. Signage is intended to increase attention (Auffrey \& Hildebrandt, 2017). Prior research suggests that visual information included on signage improves attention, recognition, and recall of information (Guenther, Klatzky, \& Putnam, 1980; Lutz \& Lutz, 1977; Shepard, 1967; Starch, 1966). Further, visual information can improve consumer judgments or attitudes (Childers \& Houston, 1984; Edell \& Staelin, 1983; Hirschman, 1986; Holbrook \& Moore, 1981; Kisielius \& Roedder, 1983). One strategy in signage that is known to increase attention is the depiction of movement using imagery. Such imagery can communicate dynamism, which can improve attitudes and increase viewer attention (Cian, Krishna, \& Elder, 2014). Dynamism in imagery is defined as imagery that can evoke a sense of movement (Cian et al., 2014). Such images are known to increase responsiveness and vigilance by increasing risk perceptions (Cian, Krishna, \& Elder, 2015). Movement can be conveyed in imagery using an individual entity or using a group of individuals that constitute related parts (Lakens, 2010). The current research examines the effects of rhythm or synchronicity in images and contributes to the literature on dynamism (Cian et al., 2014, 2015) and graphical identities (Fontaine \& Bradbury, 2018). Additionally, we explore the graphic design techniques of expressing visual rhythm and synchronicity in static imagery and the ability of this technique to convey solidarity and sense of belonging.

This area of research extends the methods for studying signage. Research in signage and wayfinding has focused on the responsiveness of regulation or sign codes (Jourdan, Strauss, \& Hunter, 2017) and legal considerations (Weinstein, 2017), and on the information included in the sign itself. Signs
Abstract /

The role of synchronicity in signage is investigated in two studies. Synchronicity has been theoretically linked to solidarity or a feeling of unity. In this research, we empirically investigate the effects of depicting synchronicity in signage using the visual principle of rhythm. Rhythm in images to create synchronicity in signage increases entitativity and a sense of belonging. We demonstrate key effects that can be leveraged in shaping consumer inferences in community and commercial contexts. Finally, we demonstrate the effectiveness of this strategy, but only when prior perceptions of belonging are absent. Implications for theory and future research are discussed.

\section{Keywords /}

Synchronicity in signage, entitativity, solidarity, trust, belonging. 
typically consist of typographic information (Bullough, 2017), which needs to be accessible, readable (Garvey, Eie, \& Klenna, 2016), and legible (Bullough, 2017). The placement within a sign (Schaefer, 2016; Symonds, 2017; Ward, 2017) and strategic placement of the sign (Apardian \& Alam, 2017) contribute to its overall success. Given that responses to signage can be cognitive, affective, or behavioral (Kellaris \& Machleit, 2016), the way information is presented in a sign is an important consideration in designing signage.

\section{SIGNAGE, VISUAL COMMUNICATION, AND GRAPHIC DESIGN}

Signage is a means of visual communication. For any representation in graphic design to make sense to the consumer, meaning inherent in visual concepts must be grounded in prior experiences (Gibbs, 2011). In this case, the prior experience of the consumer is informed by the cultural context. Spatial concepts consist of orientation that can be mapped onto concepts, which are, hence, useful in branding (Lakoff \& Johnson, 1980). The structural mapping of the meaning of these concepts on the visual field offers opportunities for communication. Movement, along with the point, line, shape, direction, tone, color, texture, and size, is an irreducible element of visual communication and source of visual information (Dondis, 1974). The ability of visual imagery to communicate movement is intriguing. In static visuals like still photos, storyboards, traffic and product label pictograms, printed advertising, and wayfinding signage, motion is an illusion; nothing is moving. Researchers have investigated how the sense of movement (dynamism) evoked by static images influences people's responses toward brands, events, facilities, places, and organizations that use or are represented by/with these images. For instance, logotypes perceived as dynamic induce a higher consumer brand engagement (longer visual attention to the logo) and, in turn, generate more favorable brand attitudes. This effect is moderated by the fitting of perceived movement with the characteristics of the brand (Cian et al., 2014). Sequel research has shown that movement perceived from static warning-sign icons induces a quicker propensity to act as compared with icons that evoke less dynamism because of the suggestion of greater risk and the increase of attentional vigilance (Cian et al., 2015).

\section{RHYTHM AND SYNCHRONICITY}

Movement may be perceived at an even frequency when the distance (or interval) between the repeated elements is identical and perceived as rhythmical when the interval between the elements varies (Leborg, 2006). In design, rhythm can be described as "a strong, regular, repeated pattern," a way to express form over time and to preserve an essential structural unity (Lupton \& Phillips, 2015). Rhythm and synchronicity can be implied in static imagery by manipulating static visual elements. For instance, a graphic designer can communicate rhythm by repeating/overlapping points, lines, shapes, colors, etc. Rhythm can be conveyed by varying these features, but with a constant variation of distance, size, direction, rotation angle, texture, transparency, etc. When two or more visual elements repeatedly change in the same pattern (rhythm), they can be perceived as performing a synchronic motion. Examples are provided in Appendix A.

Gestalt principles, which are frequently used in design, encompass synchrony in static images as "The Factor of Uniform Destiny" or of "Common Fate" (Wertheimer, 1938), positing that visual elements that were "shifted" similarly "are readily seen in the sense of one." Thus, the capacity of static graphic elements to express synchronic movement and thereby evoke a sense of "belonging together" is intuitively employed by visual communicators. For example, in synchronized swimming, athletes who perform with greater precision earn a higher score on synchronization, which is defined as "to swim or execute movements in unison, one with the other and the accompaniment" (FINA, 2013). The result of this precision is a stronger perception that the group of athletes is a single entity. Similarly, simulating synchronicity in a static image can communicate a sense of oneness or solidarity.

\section{RHYTHM AND SYNCHRONICITY}

The term solidarity represents the relationships that link the members of a group to one another. Solidarity is a feeling of devotion and enthusiasm shared by these members ("esprit de corps") and a spirit involving a 
body of affiliated actors that recognize themselves and others as belonging to the same social unit, identified as a collective entity (Hunt \& Benford, 2004). In utopian philosophy, human solidarity is achieved by seeing strangers as fellow (sufferers) and as "one of us." Solidarity can be a creative task achieved by journalists' reports, comic books, docudramas, novels, movies, and TV programs, as Rorty (1989) postulates. Strategies that can evoke feelings of solidarity include development of a robust brand identity, emotional appeals, tribalism, and rivalry. These strategies can improve brand perceptions, attitudes, and purchase behavior (Schlesinger \& Gungerich, 2011; Madrigal, 2000). When consumers identify with a brand, they become loyal and more willing to spend (Madrigal, 2000). Increased purchase intentions are a result of consumers' feelings of collectiveness, which translate into perceptions of generosity as a group norm (Madrigal, 2000). Therefore, building a brand that consumers can easily identify with is crucial and can be achieved through the adoption of group experiences, an emphasis on a unique brand history, and the creation and implementation of meaningful, ritual-type practices (Underwood, Bond, \& Baer, 2001; Watkins, 2014; Heere \& James, 2007). Sports teams provide an example of the power of solidarity via their loyal and massive fan bases who perceive themselves as part of a group, not just as consumers (Yun-Tsan, 2017; Sutton, McDonald, Milne, \& Cimperman, 1997; Heere \& James, 2007).

When consumers identify with a brand, they experience emotions that can boost positive attitudes and loyalty. Emotional appeals induce feelings of togetherness and connection between a brand and its consumers; therefore, when a brand performs well, consumers are satisfied, and brand equity is increased (Couvelaere \& Richelieu, 2005). Brands that efficaciously utilize identity and emotional appeals to create bonds with consumers innately influence negative perceptions of rival or competitive brands (Grohs, Reisinger, \& Woisetschläger, 2015; Berendt \& Uhrich, 2016). This loyalty creates a tribal aspect among consumers that stems from social recognition and socialization needs (Dionisio, Leal, \& Moutinho, 2008). Overall, brand awareness is increased (Moutinho, Dionísio, \& Leal, 2007), emotional ties are improved (Underwood et al.,
2001), brand attitudes are amplified (Schlesinger \& Gungerich, 2011), brand equity is elevated (Couvelaere \& Richelieu, 2005; Gladden \& Funk, 2002), and purchase intentions are heightened (Madrigal, 2000) for brands that create an identification bond between themselves and consumers.

In the same way that solidarity can be achieved through marketing and branding techniques, the perception of unity can be evoked by visual imagery, specifically through temporally coordinated actions depicted both in static and in moving images (Lakens, 2010). Synchronic movements are more entitative than movements in different rhythms. Previous research has shown that individuals participating in rhythmic behaviors like dancing, singing, and marching have tendencies toward social bonds, cooperation, and trust with individuals engaged in the same activity (Freeman, 2000; Wiltermuth \& Heath, 2009). We argue that solidarity or sense of belonging can be constructed via rhythm in non-behavioral messages, such as informational (e.g., signage and wayfinding) and marketing (e.g., advertising, brand experience, and sponsorship) communication. We therefore predict that an increase in synchronicity through signage will increase a sense of belonging within a given context or community. In the studies that follow, we demonstrate the incidental effects of synchronicity in signage.

\section{STUDY 1}

The objective of this study was to evaluate whether synchronicity in signage would influence feelings of solidarity or entitativity in a retail store. We predicted that a sign using images with greater synchronicity would increase perceptions of store entitativity because

\section{DESIGN}

Participants $\left(N=126, M_{\text {age }}=35.5 ; 61.9 \%\right.$ female $)$ were recruited from an online panel and offered a fee for participating. We wanted the sample to be representative of shoppers of apparel stores similar to the ones we used in the simulation and stimuli, so we included only participants who reported annual income of above $\$ 50,000$ to $\$ 75,000$. After providing consent, the participants were told that they were to take a survey 
for a retail store. They were randomly assigned to one of two conditions. Half of the participants saw the store signage with the synchronized image embedded, and the other half saw the store signage with the image that was not synchronized.

\section{PRETEST OF SYNCHRONICITY}

We conducted a pretest $(n=42)$ to confirm the synchronicity of signage. Images that varied in synchronicity were embedded with the signage (see Appendix B). The key manipulation was adapted from past literature (Lakens, 2010), in which movement was suggested in the imagery.

In this study, we relied on images that suggested movement of people walking in the same direction to suggest synchronicity. Participants in the asynchronous condition saw the store sales sign with an image of people standing still. Participants in the synchronous condition viewed the same store sales sign, but with an image of people walking in unison. Participants rated the synchronicity of the image they viewed by answering questions concerning the extent to which the figures in the sign were similar in rhythm, size, and color. These measures were adapted from Lakens (2010), and we intended that the signs would differ in rhythm, but not size or color. We selected two final images that varied on synchronicity based on participant ratings. Participants rated the sign with the asynchronous image lower on rhythm $(M=4.93 ; S D=1.67)$ than the image with greater synchronicity $(M=5.81 ; S D=$ $1.10 ; t(41)=3.61, p<.001)$. No significant variation in color $(\mathrm{p}=.36)$ or size $(p=.14)$ was reported. These two images were embedded in the store signage and in images of the store itself.

\section{PARTICIPANTS AND MEASURES}

Following simulation of the store experience, we asked each participant to study the sign corresponding to his or her randomly assigned condition. After a timed period of studying the sign, participants rated their experience in the store. Survey statements were adapted from Broekman et al. (2018) to capture perceptions of the store related to entitativity, including: I felt connected with the shoppers; I did not feel like an outsider in the store; I felt one with the store; I had a feeling of belonging with the store; and I had a feeling that I was accepted by the store. Thereafter, manipulation checks of synchronicity using the same measures as the pretest were captured. The survey ended by capturing the demographic information of the participants.

\section{RESULTS}

\section{Manipulation Checks:}

An analysis of rhythm as a function of the manipulation indicated that the manipulation worked as intended $\left(M_{\text {Low Synchronicity Sign }}=4.81 ; \mathrm{SD}=1.72\right.$ vs. $M_{\text {High Synchronicity }}$ sign $=5.47 ; S D=1.49 ; t(122.39)=2.28, p<.05)$. As expected, no significant variation in color $(p=.59)$ or size $(p=.87)$ was reported.

\section{Key Dependent Variable:}

Entitativity. An analysis of the store-related measures of entitativity ( $\alpha=.78)$ as a function of synchronicity in signage indicated that the participants specified lower entitativity when exposed to signage with lower synchronicity $(M=4.10 ; S D=2.36)$ than when exposed to signage with greater synchronicity $(M=5.61 ; S D=$ $2.25 ; t(123.17)=3.67, p<.001)$.

\section{Discussion:}

The results of this experiment indicated that visual synchronicity simulated in the imagery within a store was able to increase a sense of entitativity or belonging to the store. This visual synchronicity fostered perceptions of relating to others in the store and to the store management itself.

\section{STUDY 2}

In a store environment, the sense of control is usually higher (Baker, Grewal, \& Parasuraman, 1994), and the salience of an entity that controls an individual's experience in a space (the management) is usually evident (Baker, Grewal, \& Parasuraman, 1994). However, management is much less evident or salient in outdoor space like a park. In the next study, we wanted to evaluate whether synchronicity would influence entitativity in a space where the community is salient and whether suggested synchronicity through imagery would increase the sense of belonging to a 
community. We predicted that a feeling of solidarity or entitativity resulting from the synchronicity in signage would produce this effect.

\section{DESIGN}

Participants $\left(N=82 ; M_{\text {age }}=37.90 ; 61.0 \%\right.$ female $)$ were recruited from an online panel. They were randomly assigned to one of two conditions. As in Study 1, half of the participants saw the signage with the synchronized image embedded, and the other half saw the signage with the asynchronized image embedded. After providing consent, the participants were guided through a simulated experience of being in a park. As in Study 1 , a pretest $(n=42)$ confirmed that the images used (see Appendix $C$ ) did indeed vary on synchronicity $(M=4.14 ; S D=1.64$ vs. $M=4.90 ; S D=$ $1.39 ; t(41)=2.79, p<.01)$. No significant variation in color $(p=.66)$ or size $(p=.46)$ was reported by pretest respondents.

\section{PARTICIPANTS AND MEASURES}

Following the simulation of the park experience, the participants were asked to study the sign for their randomly assigned condition for a timed period. They were then asked to rate their experience of the park facilities. First, the participants indicated the extent of their sense of belonging to the community where the park was located by marking 1 (strongly disagree) to 7 (strongly agree) on a Likert scale in response to these statements adapted from Broekman et al. (2018): The park management is reliable; I would feel part of the community in this park; and I would experience a feeling of togetherness with the community that this park is a part of. Thereafter, manipulation checks of synchronicity using the same measures as the pretest were captured. The survey ended by capturing the demographic information of the participants.

\section{RESULTS}

\section{Manipulation Checks:}

An analysis of rhythm as a function of the manipulation indicated that the manipulation worked as intended $\left(M_{\text {High Synchronicity Sign }}=5.30 ; S D=1.31\right.$ vs. $M_{\text {Low Synchronicity Sign }}$ $=4.53 ; S D=1.68 ; t(80)=2.29, p<.05)$. As expected, no significant variation in color $(p=.33)$ or size $(p$ $=.87$ ) was reported. Although the visual elements were different from those used in Study 1, this check confirmed a replication of the manipulation.

\section{Key Dependent Variable:}

Sense of Belonging. An analysis of belonging $(\alpha=.82)$ as a function of synchronicity in signage indicated that the participants indicated less of a sense of belonging when exposed to signage with lower synchronicity $(M$ $=4.64 ; S D=1.28)$ than when exposed to signage with greater synchronicity $(M=5.26 ; S D=1.23 ; t(78.50)=$ $2.23, p<.05)$. We found a reversal of effect related to how the participants rated the sign to be complex $\left(M_{\text {High }}\right.$ Synchronicity $=3.76 ; S D=2.37$ vs. $M_{\text {Low Synchronicity Sign }}=4.94 ; S D$ $=2.32 ; t(79.52)=2.27, p<.05)$, but a consistent effect related to how they rated the informativeness of the $\operatorname{sign}\left(M_{\text {High Synchronicity }}=6.93 ; S D=1.81\right.$ vs. $M_{\text {Low Synchronicity Sign }}$ $=5.79 ; \mathrm{SD}=2.27 ; t(72.72)=2.50, p<.01)$. A mediation analysis using Hayes (2012) indicated no direct effect of synchronicity on perceptions of informativeness $(95 \% \mathrm{CI}=[-1.54 ; .14])$ but rather an indirect effect of synchronicity on perceptions of informativeness (95\% $\mathrm{CI}=[-1.07 ;-.049])$. No effect on sense of belonging based on complexity of signage was reported.

\section{Discussion:}

The results of this study revealed that participants perceived a greater sense of belonging when exposed to signage with greater (vs. lower) synchronicity.

\section{GENERAL DISCUSSION}

The present research explores the potential of signage to induce enditative responses among consumers. These studies expand prior research that focuses mainly on codes and regulations towards a more pragmatic application of signage for marketers and designers. We show that that the synchronicity viewed in signage has effects on the perceptions of context or physical space where the signage is located.

Across studies, we provide evidence that dynamism and synchronic pseudo-movements within signage create a more inclusive and welcoming environment. Synchronicity and movement are produced on signage via rhythmic and repetitive patterns. In Study 1, we 
demonstrate that when exposed to synchronous images in a retail store, consumers feel a greater sense of belonging. This feeling also translates to perceptions of elements within the store-the managers and other consumers. In Study 2, the same effect occurred. Consumers reported a greater sense of belonging to community in a park when the signage that they encountered was synchronous. Overall, we demonstrate that a sense of solidarity can be produced by rhythmic, synchronic movements in the imagery of signage.

Our findings suggest that synchronous signage in both indoor and outdoor environments is important for creating a welcoming environment where consumers feel a sense of belonging and solidarity with a brand. Therefore, the rhythm and imagery within signage should be carefully considered and implemented to create the positive effects revealed in our studies. Further research should examine which elements of signage, if any, have the potential to affect consumers who have a previously established connection with a brand.

\section{THEORETICAL IMPLICATIONS}

These studies investigate the role of synchronicity in signage and extend the prior literature about synchronicity in real life. Prior scholarship has established that synchronicity influences the observer's arousal, attitudes, and behaviors (Cian et al., 2014, 2015), creates a perception that moving parts are related (Lakens, 2010); and evokes a sense of constituting a meaningful unit (Freeman, 2000; Wiltermuth \& Heath, 2009). This current research demonstrates the effects of synchronicity through imagery on the observer's social bond.

Also, this research shows that the effects of signage on the receiver of the message are not just those literally illustrated (e.g., people/animals moving creates a sense of dynamism and synchronicity), but include cognitive, attitudinal, and behavioral responses (e.g., people/animals moving create synchronicity, which in turn leads to a sense of belonging). Thus, this work highlights the complexity of meaning-making process and the need to better understand it through its three dimensions - syntactic, semantic, and pragmatic (Morris, 1938). We propose here that semiotics, the "science of signs" frequently used in marketing and consumer behavior investigations (Mick, Burroughs, Hetzel, \& Brannen, 2004), can be a helpful theoretical and methodological approach to future research on visual signage signification.

\section{PRACTICAL IMPLICATIONS}

For professionals involved in the production signage, this investigation highlights different ways of conceptualizing a sign besides the iconic similarity and literality. Specifically, designers and art directors can explore this study to better combine visual elements and sign-making methods to create signage that evokes the desired cognitive, attitudinal, and behavioral responses. This perspective on signage goes beyond the previous emphasis on clear, literal information-sharing. The more appropriate and effective the signage, the more positive emotional and behavioral engagement can be obtained from the patrons.

\section{LIMITATIONS AND FUTURE RESEARCH}

Given that these studies were conducted in a simulated environment, one limitation of this research is that we do not evaluate effects of other sociological factors. While the studies were designed to evaluate the effect of signage, we acknowledge the fact that signage alone may not change feelings of entitativity or belonging in situations where other sociological factors could affect perceptions. Future research should evaluate the effect of the context entitativity in a non-simulated environment. 


\section{REFERENCES}

Apardian, B., \& Alam, B. M. (2017). A study of effectiveness of midblock pedestrian crossings: Analyzing a selection of high-visibility warning signs. Interdisciplinary Journal of Signage and Wayfinding, 1(2), 26-59.

Auffrey, C., \& Hildebrandt, H. (2017). Do motorists see business signs? Maybe. Maybe not. A study of the probability that motorists view on-premise signs. Interdisciplinary Journal of Signage and Wayfinding, 1(2), 100-115.

Baker, J., Grewal, D., \& Parasuraman, A. (1994). The influence of store environment on quality inferences and store image. Journal of the Academy of Marketing Science, 22(4), 328-339.

Berendt, J., \& Uhrich, S. (2016). Enemies with benefits: The dual role of rivalry in shaping sports fans' identity. European Sport Management Quarterly, 16(5), 613-634.

Bullough, J. (2017). Factors affecting sign visibility, conspicuity, and legibility: Review and annotated bibliography. Interdisciplinary Journal of Signage and Wayfinding, 1(2), 2-25.

Childers, T. L., \& Houston, M. J. (1984). Conditions for a picture-superiority effect on consumer memory. Journal of Consumer Research, 11(2), 643-654.

Cian, L., Krishna, A., \& Elder, R. S. (2014). This logo moves me: Dynamic imagery from static images. Journal of Marketing Research, 51(2), 184-197.

Cian, L., Krishna, A., \& Elder, R. S. (2015). A sign of things to come: Behavioral change through dynamic iconography. Journal of Consumer Research, 41(6), 1426-1446.

Couvelaere, V., \& Richelieu, A. (2005). Brand strategy in professional sports: The case of French soccer teams. European Sport Management Quarterly, 5(1), 23-46.

Dionisio, P., Leal, C., \& Moutinho, L. (2008). Fandom affiliation and tribal behaviour: A sports marketing application. Qualitative Market Research: An International Journal, 11(1), 17-39.

Dondis, D. A. (1974). A primer of visual literacy. Cambridge, MA: MIT Press.

Edell, J. A., \& Staelin, R. (1983). The information processing of pictures in print advertisements. Journal of Consumer Research, 10(1), 45-61.

FINA. (2013). Synchronised swimming manual for judges, coaches \& referees. Lausanne: Fédération Internationale de Natation (FINA). Retrieved from https://www.fina.org/sites/default/files/sy_manual_2013-2017.pdf

Fontaine, L., \& Bradbury, S. L. (2018). Providing brand guidance for independent businesses: A supplement to District Signage Standards. Interdisciplinary Journal of Signage and Wayfinding, 2(1), 5-33.

Freeman, W. J. (2000). A neurobiological role of music in social bonding. In B. Merker, N. L. Wallin, \& S. Brown (Eds.), The origins of music (pp. 411-424). Cambridge, MA: MIT Press.

Garvey, P. M., Eie, W. Y., \& Klenna, M. J. (2016). The effect of font characteristics on large format display. Interdisciplinary Journal of Signage and Wayfinding, 1(1). 
Gibbs Jr., R. W. (2011). Evaluating conceptual metaphor theory. Discourse Processes, 48(8), 529-562.

Gladden, J. M., \& Funk, D. C. (2002). Developing an understanding of brand associations in team sport: Empirical evidence from consumers of professional sport. Journal of Sport Management, 16(1), 54-81.

Grohs, R., Reisinger, H., \& Woisetschläger, D. M. (2015). Attenuation of negative sponsorship effects in the context of rival sports teams' fans. European Journal of Marketing, 49(11/12), 1880-1901.

Guenther, R. K., Klatzky, R. L., \& Putnam, W. (1980). Commonalities and differences in semantic decisions about pictures and words. Journal of Verbal Learning and Verbal Behavior, 19(1), 54-74.

Hayes, A. F. (2012). PROCESS: A Versatile Computational Tool for Observed Variable Mediation, Moderation, and Conditional Process Modeling, white paper, accessed June 17, 2018, http://www.afhayes.com/public/process2012.pdf.

Heere, B., \& James, J. D. (2007). Sports teams and their communities: Examining the influence of external group identities on team identity. Journal of Sport Management, 21(3), 319-337.

Hirschman, E. C. (1986). Humanistic inquiry in marketing research: Philosophy, method, and criteria. Journal of Marketing Research, 23(3), 237-249.

Holbrook, M. B., \& Moore, W. L. (1981). Feature interactions in consumer judgments of verbal versus pictorial presentations. Journal of Consumer Research, 8(1), 103-113.

Hunt, S. A., \& Benford, R. D. (2004). Collective identity, solidarity, and commitment. In D. A. Snow, S. A. Soule, \& H. Kriesi (Eds.), The Blackwell companion to social movements (pp. 433-457). Oxford, UK: Blackwell.

Jourdan, D., Strauss, E., \& Hunter, M. (2017). Sign code development process: Best practices. Interdisciplinary Journal of Signage and Wayfinding, 2(1), 34-59.

Kellaris, J. J., \& Machleit, K. A. (2016). Signage as marketing communication: A conceptual model and research propositions. Interdisciplinary Journal of Signage and Wayfinding, 1(1).

Kisielius, J., \& Roedder, D. L. (1983). The effects of imagery on attitude-behavior consistency. ACR North American Advances, $10,72-74$.

Lakens, D. (2010). Movement synchrony and perceived entitativity. Journal of Experimental Social Psychology, 46(5), 701-708.

Lakoff, G., \& Johnson, M. (1980). Metaphors we live by. Chicago, IL: University of Chicago Press.

Leborg, C. (2006). Visual grammar. New York: Princeton Architectural Press.

Lupton, E., \& Phillips, J. C. (2015). Graphic design: The new basics (2nd ed.). New York: Princeton Architectural Press.

Lutz, K. A., \& Lutz, R. J. (1977). Effects of interactive imagery on learning: Application to advertising. Journal of Applied Psychology, $62(4), 493$.

Madrigal, R. (2000). The influence of social alliances with sports teams on intentions to purchase corporate sponsors' products. Journal of Advertising, 29(4), 13-24. 
Mick, D. G., Burroughs, J. E., Hetzel, P., \& Brannen, M. Y. (2004). Pursuing the meaning of meaning in the commercial world: An international review of marketing and consumer research founded on semiotics. Semiotica, 2004(152-1/4), 1-74.

Morris, C. W. (1938). Foundations of the theory of signs. In International encyclopedia of unified science (pp. 1-59). Chicago, IL: University of Chicago Press.

Moutinho, L., Dionísio, P., \& Leal, C. (2007). Surf tribal behaviour: A sports marketing application. Marketing Intelligence \& Planning, 25(7), 668-690.

Rorty, R. (1989). Contingency, irony, and solidarity. Cambridge University Press.

Schaefer, S. (2016). A string of pearls. Interdisciplinary Journal of Signage and Wayfinding, 1(1).

Schlesinger, T., \& Güngerich, M. (2011). Analysing sport sponsorship effectiveness-The influence of fan identification, credibility and product-involvement. International Journal of Sport Management and Marketing, 9(1-2), 54-74.

Shepard, R. N. (1967). Recognition memory for words, sentences, and pictures. Journal of Verbal Learning and Verbal Behavior, 6(1), $156-163$.

Starch, D. (1966). Measuring advertising readership and results. McGraw-Hill.

Sutton, W. A., McDonald, M. A., Milne, G. R., \& Cimperman, J. (1997). Creating and fostering fan identification in professional sports. Sport Marketing Quarterly, 6, 15-22.

Symonds, P. (2017). Wayfinding signage considerations in international airports. Interdisciplinary Journal of Signage and Wayfinding, $1(2), 60-80$.

Underwood, R., Bond, E., \& Baer, R. (2001). Building service brands via social identity: Lessons from the sports marketplace. Journal of Marketing Theory and Practice, 9(1), 1-13.

Ward, N. (2017). Accessible wayfinding: Empathy, human-centered design, and a blank slate. Interdisciplinary Journal of Signage and Wayfinding, 1(2), 81-99.

Watkins, B. A. (2014). Revisiting the social identity-brand equity model: An application to professional sports. Journal of Sport Management, $28(4), 471-480$.

Weinstein, A. (2017). Legal considerations in sign code development. Interdisciplinary Journal of Signage and Wayfinding, 2 (1), 50-79.

Wertheimer, M. (1938). Special problems: First group: Perception, A. Perception and organisation, Section 5: Laws of organisation of perceptual forms. In W. D. Ellis (Ed.), A source book of Gestalt psychology (pp. 71-88). London: Routledge \& Kegan Paul.

Wiltermuth, S. S., \& Heath, C. (2009). Synchrony and cooperation. Psychological Science, 20(1), 1-5.

van Mourik Broekman, A., Gordijn, E. H., Koudenburg, N., \& Postmes, T. (2018). Reshaping social structure through performances: Emergent solidarity between actors and observers. Journal of Experimental Social Psychology, 76, 19-32.

Yun-Tsan, L. (2017). Influence of spectator motivation and team identification on team loyalty and switching intentions of sports fans. Advances in Management, 10(4), 7. 